Original article

Paediatrics Today 2015;11(2):30-39

DOI $10.5457 / \mathrm{p} 2005-114.107$

\title{
PARENTS' ATTITUDES TO A CHILD FRIENDLY DEPARTMENT
}

\author{
Vesna BUŠAC ${ }^{1}$, Aida MUJKIĆ ${ }^{2}$ Gorka VULETIĆ 3
}

${ }^{1}$ General hospital Šibenik, Pediatric Department, Šibenik, Croatia, ${ }^{2}$ University of Zagreb, School of Medicine, Andrija Stampar School of Public Health, Zagreb Croatia, ${ }^{3}$ University J. J. Strossmayer in Osijek, Faculty of Social sciences and Humanities, Croatia

Corresponding author: Aida Mujkić

Andrija Stampar School of Public Health Zagreb, Croatia aida.mujkic@mef.hr

Tel.: + 38514590134

Fax.: + 38514684441

Received: December 3, 2014

Accepted: January 28, 2015

Copyright (C) 2015 by

University Clinical Centre Tuzla. E-mail for permission to publish: paediatricstoday@ukctuzla.ba

\begin{abstract}
Objective - To investigate parents' perception of the quality of health care in the child- friendly pediatric department and to recognize parents' concern connected with organizational issues during their child's hospital stay. Participants and methods - In a period of three months in spring 2014 an anonymous questionnaire, specially designed for this research, was used on a sample of 190 parents, whose children were hospitalized. The questionnaires were delivered during the hospital stay of the child and the parents were informed about the purpose and instructed on how to fill in the questionnaire. Results Parents gave quite a high average score about overall satisfaction with the child-friendly department on the scale from 1 to 5 (Mean=4.38). The least positive scores were given for food quality, the possibilities for play and involvement in diagnostic and therapeutic procedures. Conclusions - The results of this survey confirm that parents of hospitalized children have a generally positive attitude towards the child friendly department. It is important to encourage parents to stay with children during hospitalization without any conditions.
\end{abstract}

Key words: Child friendly department - Parents' attitude - Health care quality - Croatia.

\section{Introduction}

Patient satisfaction is more than just an indicator of health care quality. Unsatisfied patients mean that health care has not achieved its goal (1). Patient satisfaction during medical procedures is the measure of the patient's perception of health care quality, and depends on the patient's expectations, values and experience (2). Measurement of satisfaction is an important tool for research planning and management (3). One of the most important reasons to measure patient satisfaction is the fact that medical diagnoses and outcomes are highly dependent on communication and active patient participation (4). This form of research helps patients to choose hospitals, and health care providers to concentrate on quality improvement and compare their own results with standards of hospital care. The results also help health care politicians in control and quality improvement, and increase competition between hospitals (5).

In accordance with the United Nations Convention on the Rights of the Child, in 1989 WHO and UNICEF introduced the Baby Friendly Hospital Initiative. The BFHI was launched in 1991 following the Innocenti Declaration of 1990 with the main goal 
to protect, promote and support breastfeeding. However the concept has much more benefits for children, mothers, families and societies as a whole than just breastfeeding. Following the global success of BFHI, a group of interested parties got together with the idea of seeing if a similar type of program could be initiated to address the many outstanding needs of children and their families treated in hospitals. Twelve standards of care were proposed and are being promoted to act as the underpinning principles of "the child friendly hospital“" (6).

The hospital or the department need to pass external assessment according to the accepted criteria to be given the title "child friendly". Healthcare workers all over the world generally have the same aspiration, to provide the best possible care for the children and families they work with. A prominent part throughout the process is the involvement of parents and children. By identifying and understanding their experiences, questions, fears and dilemmas, we can improve the health care we provide. The path to child friendly hospitals was not simple or quick. In 1959 in the United Kingdom the Ministry of Health Report: The Welfare of Children in Hospital was launched, more commonly referred to as the "Platt Report" after the Chairman of its committee, Sir Harry Platt (7). At that time parents were intentionally excluded from hospitals and only allowed to visit their sick child for a few hours a week. The almost complete separation from their families resulted in emotional disturbances varying in degree, which could have a longlasting effect.

As an audit by the Central Health Services Council (1953) revealed, only 300 out of 1,300 hospitals allowed daily visiting by parents, while 150 actually prohibited it. The situation was similar all over the world. Research by psychologists and pediatricians in the 1950s showed that the emotional stress which children experienced during hospitalization was detrimental to their emotional and psychological wellbeing. As a result, major changes began to be made, which promoted the greater involvement of families in the care of sick children, changes which gradually gained the support of health care staff. No wonder the Platt Report created a furore in hospitals across United Kingdom by advocating that "parents should be allowed to visit their sick child whenever they can and to help as much as possible in the care of their child“. Resistance by doctors and nurses to open visiting was strong and their opposition led to campaigning, over many years, by the National Association for the Welfare of Children in Hospital to have the Platt Report's recommendations implemented. It took decades.

The general aim of this research was to explore the parents' perception of the childfriendly department and to identify the problems parents face during their child's hospital stay, which influence parents' opinions, in order to define priorities for future improvement. Specific aims were to check parents' attitudes regarding the possibility of staying with the child in the hospital, breastfeeding, nursing care, physicians' care, department hygiene, food quality, possibilities for play, the possibility to take part in decisions about diagnostic and therapeutic procedures, involvement in care, safety trust in hospital stuff, and the department environment.

\section{Participants and methods}

The research was conducted at the Department of Pediatrics of the Šibenik-Knin County General Hospital in Croatia. Participants were the parents of hospitalized children aged 0 to 19 years. Data were collected over three months (January-April 2014) using a questionnaire developed for this research and validated in pilot research. During the validation of the questionnaire, the clarity of the 
questions was confirmed. Parents took part voluntarily, anonymously and individually. The questionnaires were delivered during the hospital stay of the child and the parents were informed about the purpose and instructed on how to fill in the questionnaire. The parents completed the questionnaires in the hospital department office, in privacy, before the child was discharged from the hospital. The time needed for filling in the questionnaire was 8 to 10 minutes. The department staff were informed about the research and they all agreed to it.

\section{Instrument - the questionnaire}

The questionnaire comprised 29 questions with offered answers and three open ended questions. The questions were divided into four sections: The first was about the demographic characteristics of the participant (sex, age, relationship to child, education, economic status) and the child (age, previous hospitalization, breastfeeding), the answers could be chosen from the list or written in their own words. The second group of questions consisted of 7 statements about: support for breastfeeding, overall scores for nurses, physicians and other department staff, department hygiene, quality of food, possibilities for play, and an overall score. For each statement answers were given on a 5 point Likert scale (from 1 to 5 where 1 means completely dissatisfied and 5 completely satisfied) (8). The third group of 11 statements was shaped according to "The questionnaire about patients' satisfaction in hospital" issued in 2012 by the Agency for Quality and Accreditation in Health and Social Care (9). This set of questions referred to the child's stay in the hospital, the parents' presence, the parents' participation in diagnostic procedures, care, safety and trust in hospital staff, the wider hospital environment, instructions by nurses and discharge. For each statement five numerical grades were offered (1 to 5), where 1 meant the worst score or totally incorrect statement and 5 meant the best score or totally correct statement. In the fourth part of the questionnaire it was possible to write in one's own words about the child's fears during their stay in hospital, how to make the hospital stay less stressful for the child and general suggestions for improvement of the hospital stay. The questionnaire was validated during pretesting on a small sample of parents.

\section{Ethics statement}

Parents were informed that the research had been approved by the Ethical Committee of the Zagreb School of Medicine and the Ethical Committee of the Hospital. The completed and returned questionnaires represented the parents' consent to take part in the research.

\section{Statistical analysis}

Statistical analysis was performed by statistical software Statistica 12, and Oracle. For all variables descriptive statistics were calculated. For variables with a normal distribution, mean, standard deviation, and 95\% CI were calculated. For testing the differences in categorical variables, chi-square was used. A level of significance of 0.05 was used.

\section{Results}

During the research period 245 children were hospitalized in the department, the questionnaire was given to 225 parents $(20$ children were moved to some other hospital department or other hospitals), and 190 questionnaires were completed and returned. The response rate was $84 \%$. During the research period there were 39 hospitalized infants, all of them were breastfed and all of their parents took the part in the research. Table 1 presents 
the demographic characteristics of the participants. Among the participants $82 \%$ were mothers and $16 \%$ fathers. In $2 \%$ cases there were some other relatives or persons who were taking care of the child.

Regarding previous experience with hospitalization of a child, we did not find any difference in the scores given $(\mathrm{p}=0.999)$.

115 parents used the possibility of staying with the child in the hospital for 24 hours (60\%), 51 (44\%) used apartments (they paid for it) and $64(56 \%)$ "the chair" beside the child's bed. 58 parents visited the child on a daily basis, 8 occasionally and 6 did not use any of the possibilities offered, and 3 parents did not answer that question.

The mean age of the children whose parents used the apartment was 4.3 years. In terms of the age of the children among those who used the apartments, there were 19 children below one year, 21 in the 1 to 4 years age group, 8 in the 5 to 9 years age group, 2 in the 10 to 14 years age group, 1 in the 15 to 18 years age group. The most frequent ages of the children whose parents used "the chair" was 1 to 4 years. Daily visits were most frequently used by parents of children in the 10 to 14 years age group. Table 2 shows the parents' scores for different statements.

The average score was 4.38. The scores for department hygiene did not depend on the mode of the parent's stay in the hospital. Parents only gave marks below 4 to three questions. The quality of food was scored below 4 $(\mathrm{M}=3.674 ; \mathrm{SD}=1.148)$ (Fig. 1).

The least satisfied were the parents of children in the 14 to 19 years age group. The parents of lower economic status gave significantly higher marks $(\mathrm{p}<0.05)$. We did not find any difference regarding the parents' educational level. Parents who used the apartments gave better marks to the quality of food $(\mathrm{p}<0.05)$. The possibility for play was also given a score below 4 (Mean=3.582, $\mathrm{SD}=1.283$ ) (Fig. 2).

\section{Table 1 Main characteristics of participants}

\begin{tabular}{|c|c|}
\hline Characteristics & n $(\%)$ \\
\hline \multicolumn{2}{|l|}{ Sex } \\
\hline Female & $157(82.7)$ \\
\hline Male & $33(17.3)$ \\
\hline Total & $190(100)$ \\
\hline Age (years; mean $\pm S D$ ) & $35.44 \pm 6.927$ \\
\hline Age of schooling (years; mean \pm SD) & $13.04 \pm 2.63$ \\
\hline \multicolumn{2}{|l|}{ Level of education } \\
\hline Primary school & $6(3.1)$ \\
\hline Secondary school & $109(57.3)$ \\
\hline High school & $75(39.5)$ \\
\hline \multicolumn{2}{|l|}{ Family's economic status* } \\
\hline Much below average & $5(2.7)$ \\
\hline Below average & $15(7.9)$ \\
\hline Average & $138(72.6)$ \\
\hline Above average & $26(13.7)$ \\
\hline Much above average & $2(1.0)$ \\
\hline Children's age (years; mean \pm SD) & $6.342 \pm 5.826$ \\
\hline \multicolumn{2}{|l|}{ Children's age group (years) $\dagger$} \\
\hline Below one year & 39 (20.6) \\
\hline 1 to 4 & $62(32.6)$ \\
\hline 5 to 9 & $29(15.2)$ \\
\hline 10 to 14 & $34(17.9)$ \\
\hline 15 to 19 & $24(12.6)$ \\
\hline \multicolumn{2}{|l|}{ Hospitalization } \\
\hline First hospitalization & $69(36.3)$ \\
\hline Previous hospitalization $\min =1 ; \max =20$ & $121(63.7)$ \\
\hline \multicolumn{2}{|c|}{ Parents' 24 hours stay in hospital $(\mathrm{n}=115 ; 60.5 \%)$} \\
\hline Apartment & $51(26.8)$ \\
\hline Chair & $64(33.7)$ \\
\hline \multicolumn{2}{|l|}{ Food of children during hospitalization } \\
\hline Breastfeeding & $39(20.5)$ \\
\hline Food adapted to age of child & $151(79.5)$ \\
\hline
\end{tabular}

*Four parents did not enter the family's economic status and $\dagger$ two age of child.

The worse marks were given by parents of younger children, aged 1 to 4 years and 5 to 9 years. Parents in the average economical 


\begin{tabular}{|c|c|c|c|c|}
\hline Scores & $\mathrm{n}$ & Mean & SD & $\mathrm{CI}$ \\
\hline Scores for nurses & 180 & 4.50 & 0.80 & $0.72-0.89$ \\
\hline Scores for physicians & 179 & 4.49 & 0.80 & $0.72-0.89$ \\
\hline Scores for other stuff & 180 & 4.43 & 0.87 & $0.79-0.97$ \\
\hline Scores for department hygiene & 182 & 4.31 & 0.88 & $0.80-0.98$ \\
\hline Scores for food quality & 178 & 3.67 & 1.14 & $1.03-1.28$ \\
\hline Possibility for play & 165 & 3.58 & 1.28 & $1.15-1.43$ \\
\hline Overall scores & 180 & 4.38 & 0.76 & $0.69-0.85$ \\
\hline Rooming in helps the child & 188 & 4.89 & 0.34 & $0.31-0.38$ \\
\hline Rooming in helps the parents & 184 & 4.78 & 0.63 & $0.57-0.70$ \\
\hline Participation ${ }^{*}$ & 172 & 3.58 & 1.37 & $1.24-1.53$ \\
\hline Presence with child ${ }^{\dagger}$ & 180 & 4.50 & 0.92 & $0.83-1.03$ \\
\hline Safety and trust in health professionals & 185 & 4.38 & 0.82 & $0.74-0.91$ \\
\hline Warm and friendly environment & 185 & 4.53 & 0.79 & $0.72-0.88$ \\
\hline Clear information from nurses & 184 & 4.48 & 0.84 & $0.76-0.93$ \\
\hline Clear information from physicians & 185 & 4.42 & 0.86 & $0.78-0.96$ \\
\hline Instructions before discharge ${ }^{\S}$ & 169 & 4.61 & 0.67 & $0.60-0.75$ \\
\hline Instructions before discharge about further steps & 167 & 4.61 & 0.69 & $0.62-0.77$ \\
\hline
\end{tabular}

"In diagnostic and therapeutic procedures; ${ }^{\circ}$ During diagnostic and therapeutic procedures; ${ }^{\varsigma}$ From whom and when to seek help.

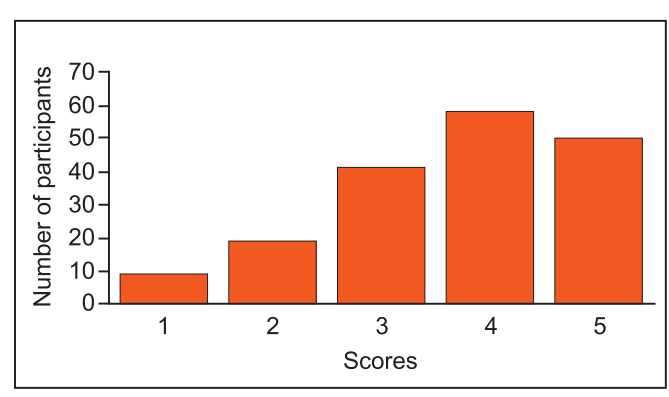

Fig. 1 Quality of food.

group gave significantly higher scores compared with parents in the higher economical group $(\mathrm{p}<0.05)$. Parents who belonged to the higher educational level group gave a lower score $(\mathrm{p}<0.05)$. The marks were as follows: parents with elementary school, Mean $=4$; parents with secondary school, $M=3.714$; parents with college or university, $\mathrm{M}=3.392$. Parents who used apartments mostly gave a score of 5, users of "the chair" 3, and daily visitors 4 . The possibility to be involved in

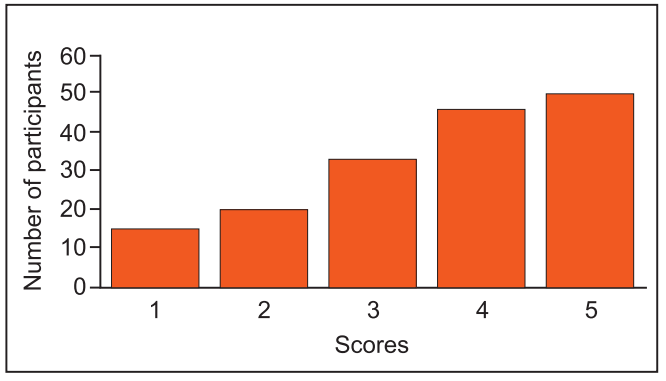

Fig. 2 Possibilities for play.

the diagnostic and the therapeutic procedures was also scored below 4 (Mean $=3.581$, $\mathrm{SD}=1.376$ ) (Fig. 3).

The scores were as follows: parents with elementary school, Mean $=4.333$; parents with secondary school, $\mathrm{M}=3.702$; parents with college or university, $M=3.463$. Regarding the child's age, the most dissatisfied parents were those of children aged 0 and 1 to 4 years. 39 children were breastfed during their 


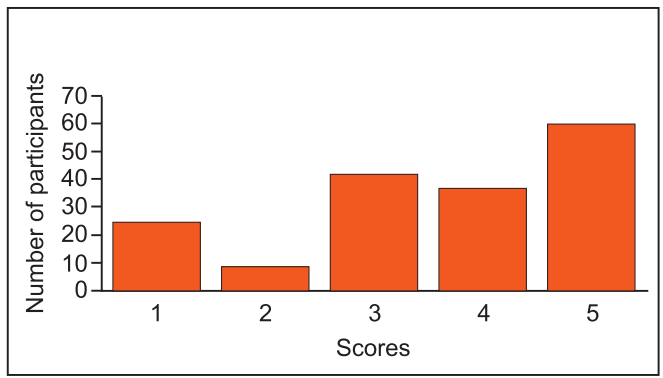

Fig. 3 Involvement in diagnostic and therapeutic procedures. hospital stay, the average score for breastfeeding support was 4 (Mean=4.368; $S D=1.148)$.

In the last three questions parents expressed their opinion and gave advice (Fig. 4 and 5).

52 parents praised the work of the physicians and nurses, 44 advised better communication, 6 noticed the lack of staff. Other comments were about the price parents pay to stay 24 hours with the child, the need for more colorful uniforms, improvement of

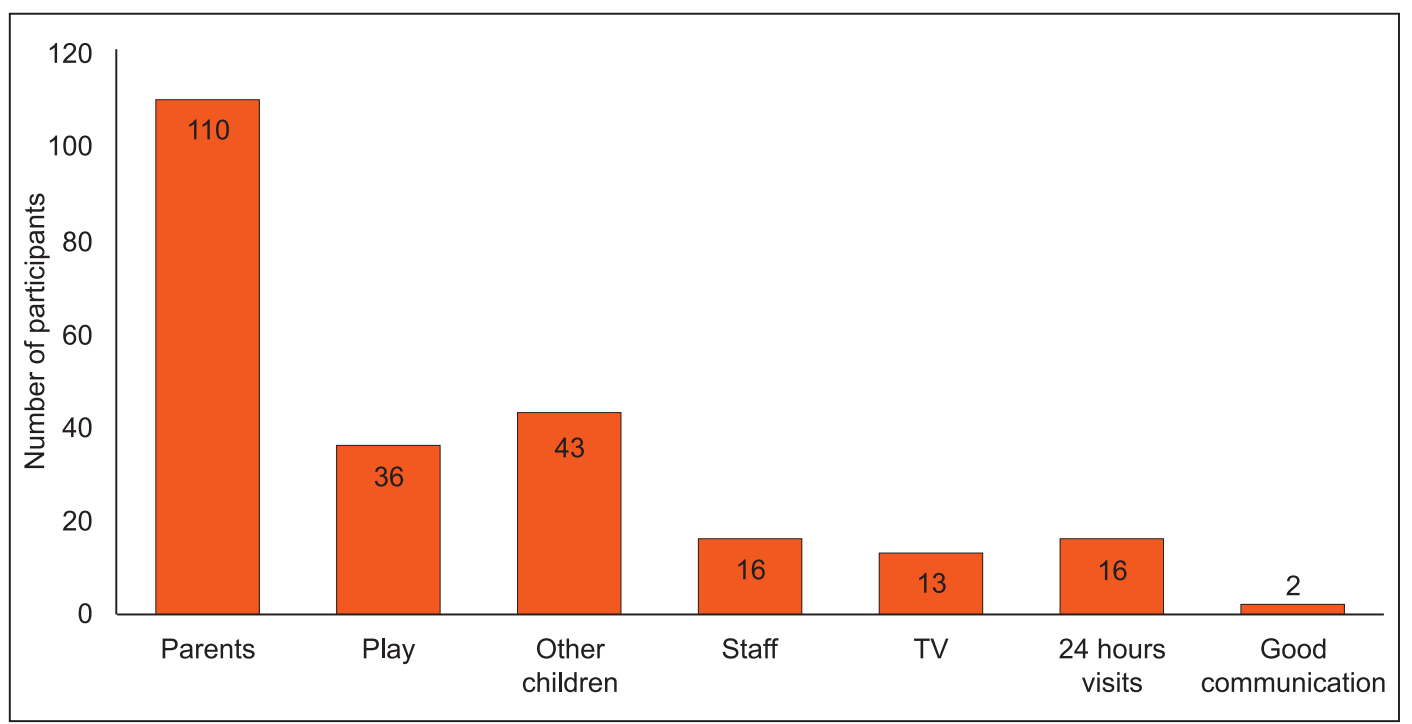

Fig. 4 What made the stay in hospital easier for the child?

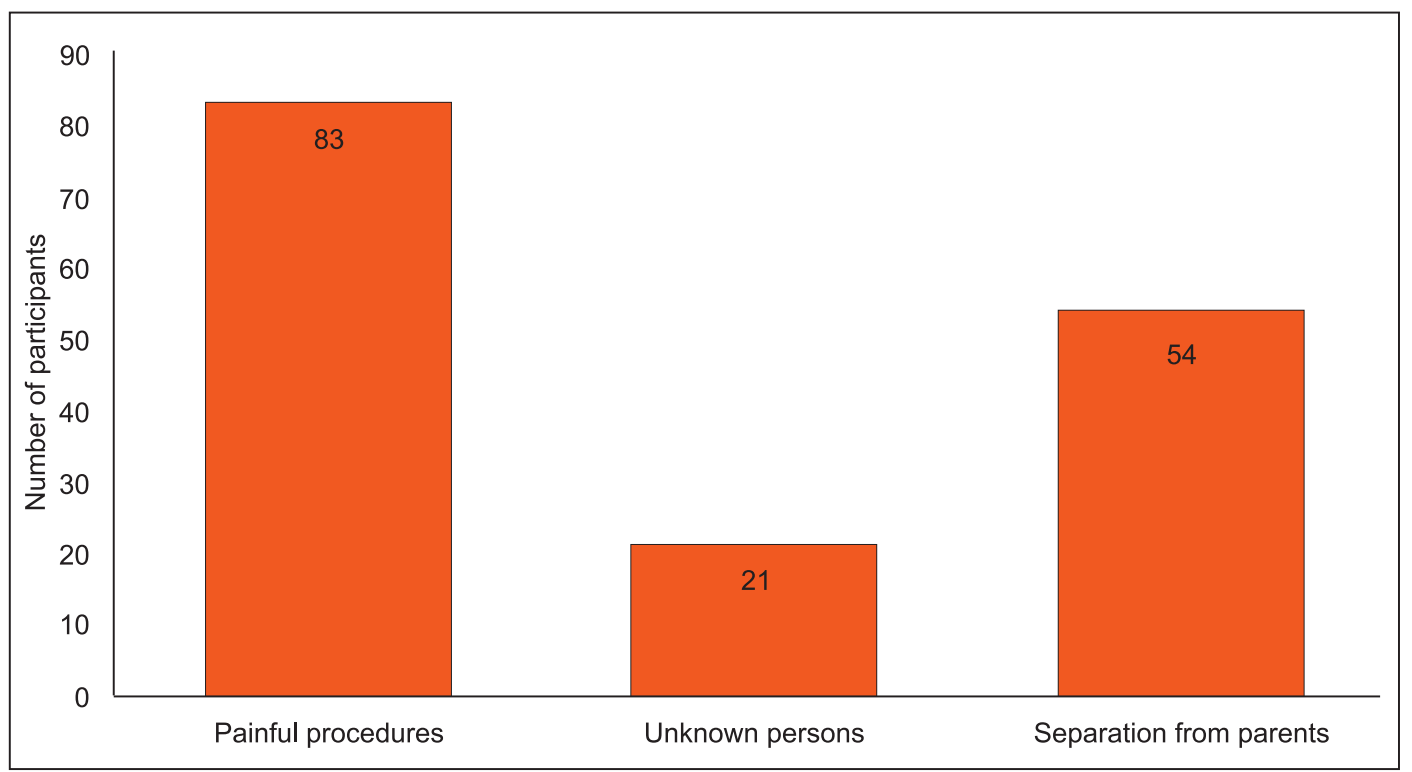

Fig. 5 What made child the most afraid during the stay in hospital? 
the quality of food, education about disease prevention, the need for more time given by nurses and physicians for information about the health of the child and more time spent with the child. The average value on the Likert scale was 4.356 .

\section{Discussion}

This research was focused upon care given to children, hospitalized at the General Hospital in Šibenik, Croatia, in the pediatrics department, which has the title „Child- friendly department". The Department was in the process of obtaining the prestigious title "childfriendly" for ten years and was granted it in 2009. Regarding the whole child-friendly concept, it is interesting to mention, which is not very well known even among professionals, the example of the very progressive approach in the General Hospital in Tuzla, Bosnia and Herzegovina (at that time part of Yugoslavia), where the children's department had 150 beds for children and 60 beds for attendant mothers. Since its establishment in 1952 this department has admitted the mother of every child under 3 years of age and even as old as 14 years in the case of a serious disease, with the main aim to decrease the psychological stress of the hospitalized child and mother. An article about the practice in Tuzla hospital, where an important figure was the physician Žarko Mičić, was published in the International Nursing Review in 1962 (10).

In our research, the total percentage of questions answered was high, $87.1 \%$. Parents expressed their motivation to take part in the research, which indirectly demonstrates how motivated they were to improve hospital conditions for their child. Generally, parents expressed very positive attitudes regarding their hospital experience, on the 1 to 5 scale the overall average mark was 4.356. Nursing care was given a score of 4.50 and of physicians
4.49. Most participants were mothers, which reflects the still traditional relationships in families where mothers are those who dominantly take care of the children in health and sickness. The great majority of participants declared their economic status as average.

According to the children's age, the largest group, one-third of the children was aged 1 to 4 years. In Neill's research from 1996 they found that parents of the same age group, hospitalized even once for a short period, mentioned difficulties in caring for them (11). Over two-thirds of parents in this research had the experience of a previous hospitalization of their child but we did not find any difference between them and the parents for whom this hospitalization was the first. The possibility to stay with the child for 24 hours was used by $60 \%$ of parents, mainly for younger children. A possible limitation on the higher usage of that possibility could be the additional costs for staying 24 hours with their child. When they stay with a child in the hospital, parents need to reorganize their whole professional and family life (12). All children under the age of one year were breastfed during the hospital stay and the parents gave a high score (above 4) for breastfeeding support.

Analysis of the statements generally confirmed the parents' positive attitude, with scores above 4 . Only three sections were given a score below 4: the quality of food, possibilities for play, and parents' involvement in diagnostic and therapeutic procedures. Despite the fact that quality of food, as well as the possibility to play probably depend more on financial resources, these fields are evidently in need of improvement. The worst scores for food quality were given by the parents of children in the 15 to 19 years age group, which could be connected with the fact that teenagers are generally more challenging regarding nutrition. Parents of lower economic status gave better marks, probably 
their expectations are lower. It is interesting that we did not find any connection between educational status and scores for food quality.

Regarding the possibility for play, the worse scores were given by the parents of the youngest children. Parents with above average economic status and with a higher educational level gave worse scores. Probably they have higher expectations and have better insight into the different possibilities for play, so they are more critical. Parents who used apartments mostly gave a score of 5 , which is connected with the fact that mainly parents of younger children used apartments, and infants and small children could be satisfied with simpler and readily available toys. Despite the very well-known and recognized benefits of playing for children, the hospital setting has some specificities regarding the possibility to play and sometimes because of health reasons the possibilities for play are quite restricted (infectious disease, the need to rest, tiredness of the child, sterile conditions). The lowest score was given to participation in diagnostic and therapeutic procedures. The best marks were given by parents with elementary school education and a below average economic status. The lowest score was given by the parents of children aged below one year and 1 to 4 years, and with above average economic status. Beside the Child Friendly Hospital Initiative, the European Association for Children in Hospital Charter (EACH Charter) from 1988 (originally called the "Leiden Charter") also says: "Children and parents have the right to informed participation in all decisions involving their health care. Every child shall be protected from unnecessary medical treatment and investigation (13). $3 \%$ of our parents said that they did not have any possibility to take care of their child. The percentage could seem low but it is a warning sign to pay more attention to this issue.
The presence of a parent in the hospital with the child could significantly decrease the child's stress, and many positive outcomes have been recorded, such as lower usage of painkillers, antibiotics, shorter hospitalization and so on. However, the situation is not simple because parents on the one hand want to be involved, but also they express their lack of information and some insecurity and fear (14). They also mentioned the professional "power" of health professionals who sometimes do not want to share information with parents, or if they recognize that the parents are more competent, they place too heavy a burden of responsibility on the parents (15). Sometimes parents have the feeling that their role in care is not taken seriously into consideration (16).

Health professionals need to understand that more information about the child given to the parents means greater trust in the physicians (17). Beside the relationship with the child and parents, the relationships between the department members are also important. Good interpersonal relationships mean better quality of health care (18). Good organization is important for both the staff and patients (19).

In our research, the parents expressed a positive impression regarding the interpersonal relationships among the department staff. Health professionals should be involved in psychological interventions for reducing pain and distress (20). The quality of communication is always mentioned as a significant part of health care as a whole (21). Our research confirmed this and the parents stressed the importance of improving communication. Sufficient information as part of good communication is crucial for the partnership between the children, parents and staff $(22,23)$. Good communication is also connected with patient compliance to health professionals' advice (24). The insufficient number of health professionals is a 
serious obstacle to providing high quality health care, and this problem is increasingly present in Croatia. Some parents noticed this and commented on this in the last part of the questionnaire, when they had the possibility to write their own free text.

\section{Limitations of the study}

The limitations of the study are the small number of participants from only one childfriendly department. Also, the participants' educational status was above average so the results could not be generalized to the general population of parents.

\section{Conclusion}

Our research confirmed very clearly that parents want and need child friendly hospitals/ departments and that they are willing to take an active part in the hospitalization of their children. We need to make more effort to make this possibility available for all children without any limitations.

Authors' contributions: Conception and design: AM, $\mathrm{VB}$; Acquisition, analysis and interpretation of data: VB, AM, GV; Drafting the article VB, AM; Revising it critically for important intellectual content: VB, AM, GV.

Conflict of interest: The authors declare that they have no conflict of interest.

\section{References}

1. Vuori H. Patient satisfaction: does it matter? Qual Assur Health Care. 1991;3(3):183-9.

2. Thiedke CC. What do we really know about patient satisfaction? Fam Pract Manag. 2007;14(1):33-6.

3. Brook RH, Lohr HN. The definition of quality and approaches to its assessment. Health Serv Res. 1981; 16(2):236-7.

4. Cleary PD, McNeil BJ. Patient satisfaction as an indicator of quality of care. Inquiry. 1988;25(1):25-36.

5. Reeves R, Seccombe I. Do patient surveys work? The influence of national survey program on local quality-improvement initiatives. Qual Saf Health Care. 2008;17(6):437-41.

6. Southall DP, Burr S, Smith RD, Bull DN, Radford A, Williams A, et al. The Child-Friendly Healthcare Initiative (CFHI): Healthcare provision in accordance with the UN Convention on the Rights of the Child. Child Advocacy International. Department of Child and Adolescent Health and Development of the World Health Organization (WHO). Royal College of Nursing (UK). Royal College of Paediatrics and Child Health (UK). United Nations Children's Fund (UNICEF). Pediatrics. 2000;106(5):1054-64.

7. Lightwood R, Craig WS, Harvey CC, McCarthy D, Mac Keith R, Pinchney C, et al. The Welfare of Children in Hospital. Br Med J. 1959;1(5115):166-9.

8. McLeod SA. Likert Scale. 2008. [cited 2015 January 11]. Available from: http://www.simplypsychology.org/likert-scale.html.

9. Agency for Quality and Accreditation in Healthcare. Manual on quality standards of health care and the manner of their application. (on Croatian) AAZ. Zagreb, September 2011;87-9.

10. Micic Z. Psychological Stress in Children in Hospital. Int Nurs J. 1962;6(9):23-31.

11. Neill SJ. Parent participation. 1: Literature review and methodology. Br J Nurs. 1996;5(1):34-40.

12. Lam LW, Chang AM, Morrissey J. Parents' experiences of participation in the care of hospitalized children: a qualitative study. Int J Nurs Stud. 2006;43(5):535-45.

13. EACH: European Association for Children in Hospital. The 10 articles of the EACH Charter [homage on the Internet].1988 [cited 2014 May 11]. Available from: http://www.each-for-sick-children.org/each-charter/the-10-articles-of-the-eachcharter.html.

14. Coyne IT. Parental participation in care: a critical review of the literature. J Adv Nurs. 1995;21(4):716-22.

15. Darbyshire P. Parents, nurses and pediatric nursing: a critical review. J Adv Nurs. 1993;18(11):1670-80.

16. Reeves E, Timmons S, Dampier S. Parents' experiences of negotiating care for their technology-dependent child. J Child Health Care. 2006;10(3):228-39

17. Huang IC, Kenzik KM, Sanjeev TY, Shearer PD, Revicki DA, Nackashi JA, et al. Quality of life information and trust in physicians among families 
of children with life-limiting conditions. Patient Relat Outcome Meas. 2010;2010(1):141-8.

18. Weisman CS, Nathanson CA. Professional satisfaction and client outcomes. A comparative organizational analysis. Med Care. 1985;23(10):1179-92.

19. Shortell SM, O’Brien JL, Carman JM, Foster RW, Hughes EF, Boerstler H, et al. Assessing the impact of continuous quality improvement/total quality management: concept versus implementation. Health Serv Res. 1995;30(2):377-401.

20. Chambers CT, Taddio A, Uman LS, McMurtry CM; HELPinKIDS Team. Psychological interventions for reducing pain and distress during routine childhood immunizations: a systematic review. Clin Ther. 2009;31 (Suppl 2)S77-S103.
21. Homer CJ, Marino B, Cleary PD, Alpert HR, Smith B, Crowley Ganser CM, et al. Quality of care at a children's hospital. Arch Pediatr Adolesc Med. 1999;153(11):1123-9.

22. Hummelinck A, Pollock K. Parents' information needs about the treatment of their chronically ill child: a qualitative study. Patient Educ Couns. 2006;62(2):228-34.

23. Marino BL, Marino EK. Parents' report of children's hospital care: what it means for your practice. Pediatr Nurs. 2000;26(2):195-8.

24. Nobile C, Drotar D. Research on the quality of parent-provider communication in pediatric care: implications and recommendations. J Dev Behav Pediatr. 2003;24(4):279-90. 